\title{
Research on the Advantages of Production and Communication of Online Short Films in China
}

\author{
Wenjia Tang \\ Faculty of Arts \& Humanities \\ University College London \\ London, the United Kingdom
}

\begin{abstract}
An online short film is a form of art in a new media era which combines traditional film art and the rapiddeveloping Internet technology. With the growing influence and spread of online short films, relevant discussions emerge as the times require. It is because of the uniqueness of the new media platform and the online short film itself to break through the traditional presentation mode, which provides an opportunity for such films to develop a new boundary of producing, and also provides a unique advantage for them to seize the opportunities in the market. This essay will briefly analyze the advantages of Chinese online short films in its dissemination and production.
\end{abstract}

Keywords—short films; internet; new media; communication

\section{INTRODUCTION}

Internet technology has been used in the field of media and communication for a long-term, which has changed the people's behavioural pattern and thinking pattern in many aspects (Choi, 2013). The Internet-based information is not only a new invention under technological innovation but also a unique characteristic of modern society. The short film is such a new communication mode and art form that relies on the characteristics of the Internet platform. With the expansion of the influence of the Internet, to meet the needs of Internet users, in other words, the needs of their target audiences. Online short films not only challenge the way of narrative production of traditional film works but also change the audience's acceptance habits of film and videos with its unique aesthetic discourse. They reshape the communication mode of video in the process of showing online and leave an indelible mark in the new media era. This essay is going to talk about the advantages of Chinese online short films in production and communication. In the first part, the different production mode of short films will be discussed and compared to traditional ones. The audience's entertainment and aesthetic needs for short films will also be considered in this section. Secondly, in the latter part, the communication strategy and process of short films will become the main research object. This part will discuss why short video can spread rapidly on the Internet in today's Chinese market.

\section{THE INNOVATION OF THE AUDIENCE-PARTICIPATION MOdEL IN THE PRODUCTION OF SHORT FILMS}

With the further influence of the wave of cultural globalization on the Chinese mass media, more media have concentrated on new products which can reflect the modern lifestyle and the society. The rapid development of Internet technology has spawned a new media communication platform and an emerging film style called online short film. It is not only a component with distinctive features of the times of Chinese contemporary culture but also the most concerned and popular film art form. Online short films not only inherits the advantages of traditional cinemas but also be proper to the media contact habits of modern people. Therefore, they can gain high popularity and acceptance in today's market.

The development of the Internet provides new opportunities for the creation of short films. New media has changed the audience's behavioural pattern and thinking pattern, which is reflected in the changes in new media practitioners' creative ideas of short films. The emphasis on selection and participation of the audience has become the direction of short film reform.

Firstly, compared with monotonic text and audio, the output of films can bring more audio-visual impact to the audience and convey more information. Online short films can express contents through multiple media, and apply various expressive techniques, such as sound, image, text, to the presentation of short films. Moreover, with the support of Internet platform, the communication between users and these media can be realized to form "interactivity". When audiences receiving from those films, they can not only intuitively understand the contents but also deepen their memory of images and pictures. Moreover, the new media platform actively seize users' fragmentary time by passing text and voice messages to them. The highly respected information is likely to be replaced by short films. Short films can attract users who cannot concentrate on reading. Nevertheless, the transition from single media to multimedia is the trend of Internet development. It can be predicted that more communicators will pay attention to short films and achieve the purpose of marketing propaganda by shooting short films in the vigorous development of new media. Information dissemination through short films adapts to the 
change of the market and effectively meets the demands of users.

In addition, online short films pursue unconventional creation in content expression. Traditional film and television works tend to slow storytelling, which is no longer suitable for text content selection in short films. Online short films tend to tell stories with novel and peculiar subject themes which are seldom involved in television and film media. It can be found that many online short films are created based on the text of network novels with unrestrained themes and fantastic conceptions. These are topics which are unique to the audiences. Based on the development of special effects animation technology, the contents and themes strange for the audience are adapted to films, which can strengthen visual expression and meet the audience's psychological needs of seeking novelty.

Secondly, online short films pay more attention to audiences' feedback and participation in production. New media has changed the way how audiences behave and how they considerate. This allows audiences to participate more naturally in the content selection and second creation of films. It can be said that the online short film is a sample of work with is co-created by professional producers and audiences.

The audience of short films is the target group of demassification. With a clear positioning and defining the scope for age, gender and educational background of their appropriate audience, short films are generally created to cater to their expected elements. Because of the detailed division, the audience's acceptance of psychology and the expected way of behaviour have higher practical values. Determining the works favoured by the target audience is the first step for filmmakers' choices: Clarify the taste of the target audience, and incorporate the factors of their favourite works into the pre-production selections; and then further strengthen the arrangement of the details in the creative plots and characters. The feedback from the audience makes films as close as possible to the audience's expectations and achieves the purpose of attracting more of them.

On some websites and platforms, when the audience is watching and enjoying the film, they can not only realize real-time interaction through danmaku, a real-time comment system which can only be implemented on the Internet platform but also evaluate and forward the films. These have changed their single identity as Internet users. The audience's discussion will appear when other audiences watch films and participate in information acceptance, thus forming the secondary information interaction. In this case, the audiences who publish comments are not only recipients but also information sources of other audiences. As a result, participants are more likely to be involved in watching, evaluating, and appreciating films, and become a part of the film reproduction. This is the two-way interaction that cannot be provided by the traditional film and television works.

\section{NeW Media AS THE Optimal COMMUNiCATION CARRIER OF SHORT FILMS}

Since the internet linked channels between China and foreign countries were officially opened, the development of new media in China is booming. For the first time, netizens, as internet users, can read and publish information across time and geographical constraints through the network media. Later, micro-blog and $\mathrm{WeChat}$ began to be popularized, and the characteristics of the Internet era have changed significantly. Different from the crowding form of traditional media, new media enables the audience to spread contents without gathering in a certain place at a specific time. They can watch the same films at the unfixed time so that the location of the audience is no longer important. Location and time do not restrict the appreciation of new media contents. New media environment provides a broader platform for short film shooting and sharing. Firstly, the network has freer requirements for the form of the published contents than a traditional media platform and it is more suitable for the communication and exchange of various forms of works. Secondly, the widespread in network environment requires novelty and uniqueness in content selection. Short films break the old pattern that audiences have been tired of. They make up for the types of works lacking in traditional platforms and focus more on the impact of content and form, which attract young people who pursue sensory satisfaction.

The whole process of short films from creation to dissemination is based on large-scale diffusion. The traditional state of video communication is "single-time", pursuing for completion; while the dissemination of online short films is "multiple", which pursues the breadth of communication. As a large group of Internet users may become a re-distributor of short films, and each user has its potential to spread the influence, after multiple stacks, more users can watch those films on the new media platform. The heat is built up to increase its influence. The open network just has the characteristics of a derivative, which is more favoured by the producers of short films.

Online short films do not simply get profits through single pricing, but focusing on the expansion of the radiation range and the industrial chain of subsequent derivatives. This is the creation of brand value and a necessary condition for sustainable operation. As the bearer of independent property rights, new media platform not only supports the introduction of emerging brands but also provides a considerable potential customer base for its long-term development, which explains why short films are generally played on new media platforms.

Users' behaviour has changed due to the prevalence of new media platforms. Traditional users like to watch films in a fixed time and places. In such watching mode, the duration of watching is continuous and dispense with the interference from other aspects so as to realize a "ritual" effect. New media platform pushes films at the scattered and idle time. Its users can be easily immersed in the story without continuous watching so that the watching form is more flexible. 
In addition, the relationship between the audience and the media tends to be equal on the network platform. The communication platform no longer forces the audience to pay advertising fees, but selectively pushing short film works and giving the initiative back to the audience. They can either watch ads to offset the cost or pay for copyright. This two-way selection is made by the audience, rather than a broadcast profit scheme similar to television and cinema.

Since the audience volunteer to search and appreciate the contents and products, the selection of content has become their right. It is necessary to understand the psychological state of the audience in order to gain a favourable position in the interaction between the two sides. From a psychological point of view, the selective memory of the audience is a long-term habit which can hardly be changed. The audience believes in their choices. Thus, short film creators should be closer to their needs, understand and observe their choices and make appropriate analysis so as to achieve better communication purposes. In the powerful operation mode, the producers can form their unique style through image information and establish a good interactive relationship with the audience. There is a mutual trust relationship between the producers of short films who have their style and the audience who appreciates the style, and they will always be the choice of the other side.

It is worth noting that the audience still cares more about the contents. They implement communication and propaganda according to their interest and preference. There is no clear distinction between authors and receivers in the new media environment. Free choice and timely information feedback provide relatively large space for the propagation of short films. Film production and appreciation modes also break the internal and external barriers to achieve interaction. The propagation of short films is neither directed nor unidirectional. All audience is likely to be the centre of information. They further propagandize information to the potential audience around themselves, so that the scope of communication is expanded as much as possible. In this case, new media as a communication platform has more obvious advantages.

\section{CONCLUSION}

In summary, based on the characteristics of communication platforms and the originality of production, online short films have implemented great changes and breakthroughs compared with traditional film and television works, which has caused widespread concern and discussion in the modern Chinese market with the rapid development of media influence. How new media practitioner should create excellent works with rich aesthetic connotation while attracting extensive attention through the unique advantages of short films in communication and production has become an issue to be concerned about in the future development of the market.

\section{REFERENCES}

[1] S. Choi, and Y. Han. "Representative reviewers for Internet social media," Expert Systems with Applications. 40(4), pp.1274-1282, 2013.

[2] P. Liang, and S. Guo. "Social interaction, Internet access and stock market participation - An empirical study in China," Journal of Comparative Economics. 43(4), pp.883-901, 2015.

[3] M. Cernikova, L. Dedkova, and D. Smahel. "Youth interaction with online strangers: experiences and reactions to unknown people on the Interne,t” Information, Communication \& Society. 21(1), pp.94-110, 2016.

[4] G. Pirelli, R. Otto, and A. Estoup. "Using internet and social media data as collateral sources of information in forensic evaluations," Professional Psychology: Research and Practice. 47(1), pp.12-17, 2016. 